ESPAÇO TEMÁTICO: TERRA, TERRITÓRIO E AMÉRICA LATINA

\title{
O MST e a agroecologia: entre autonomia e subalternidade
}

\author{
Luciana Aliaga ${ }^{1}$ \\ https://orcid.org/0000-0001-7842-715X
}

\author{
Fernanda Maranho ${ }^{2}$ \\ https://orcid.org/0000-0001-8596-6696
}

${ }^{1}$ Universidade Federal da Paraíba, Departamento de Ciências Sociais, Programa de Pós-graduação em Ciência Política e Relações Internacionais, João Pessoa-PB, Brasil

${ }^{2}$ Universidade Federal da Paraíba, Departamento de Ciências Sociais, Programa de Pós-graduação em Ciência Política e Relações Internacionais, João Pessoa-PB, Brasil

\section{O MST e a agroecologia: entre autonomia e subalternidade}

Resumo: O objetivo deste artigo consiste na análise do período de reorganização político-estratégica do Movimento dos Trabalhadores Rurais Sem Terra (MST), compreendido entre 2000 e 2016, que se centrou na proposta de implantação da educação ambiental e da promoção da agroecologia em seus assentamentos e cooperativas de produção. Por meio de análise documental, bibliográfica e empírica constatou-se a existência contraditória de elementos que definem e articulam dois caminhos opostos: por um lado, a criação de uma via de autonomia intelectual, política e econômica a partir da organização coletiva, da educação e da formação técnica de uma porção significativa de trabalhadores rurais e, por outro, um processo de subalternização das lideranças sem-terra pelos governos do Partido dos Trabalhadores (PT), que redundou no estancamento da reforma agrária no Brasil.

Palavras-chave: MST. Reforma agrária. Agroecologia. Brasil.

The MST and agroecology: between autonomy and subordination

Abstract: The aim of this article is to analyze the period of political-strategic reorganization of the Landless Rural Workers Movement (MST), between 2000 and 2016, which focused on the proposal to implement environmental education and promote agroecology in its settlements and production cooperatives. Through documentary, bibliographic and empirical analysis, the contradictory existence of elements that define and articulate two opposing paths was found: on the one hand, the creation of a path of intellectual, political and economic autonomy from collective organization, education and the technical training of a significant portion of rural workers and, on the other hand, a process of subordination of landless leaders by the Workers' Party (PT) governments, which resulted in the stagnation of the agrarian reform in Brazil.

Keywords: MST. Agrarian reform. Agroecology. Brazil.

Recebido em 02.03.2021. Aprovado em 15.05.2021. Revisado em 16.07.2021.

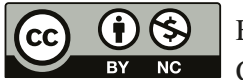

Este é um artigo publicado em acesso aberto (Open Access) sob a licença Creative Commons Attribution NonCommercial, que permite uso, distribuição e reprodução em qualquer meio, sem restrições desde que sem fins comerciais e que o trabalho original seja corretamente citado. 


\section{Introdução}

Nestas quatro décadas de existência e resistência do Movimento dos Trabalhadores Rurais Sem Terra $(\mathrm{MST})^{1}$, frente às subsequentes conjunturas hostis, com altos índices de violência no campo e assassinatos de trabalhadores rurais ${ }^{2}$, foram necessárias diversas reorganizações internas e mudanças estratégicas para que o movimento pudesse não apenas sobreviver, mas também se estabelecer nacionalmente (FERNANDES, 2000). Na primeira metade da década de 1980, que marcou seus anos iniciais de vida, o MST buscou preferencialmente a negociação pelas vias institucionais com os governos, mediada pelos padres católicos das Comunidades Eclesiais de Base (CEBs) e da Comissão Pastoral da Terra (CPT). Por meio desta estratégia, tentou colocar a reforma agrária na agenda do Estado, a partir do direito legítimo aos meios de sobrevivência, expresso pela palavra de ordem Terra para quem nela trabalha (NAVARRO, 2002). A partir da segunda metade da década de 1980, contudo, observou-se um deslocamento da opção preferencial pela via da negociação para as ações diretas (ocupação de terras e de prédios públicos, além de greves de fome), evidenciando a crescente autonomia das direções dos trabalhadores sem-terra em relação às pastorais católicas (ALIAGA, 2008). O maior nível de radicalidade e enfrentamento nas ocupações de terra se expressou no lema desse momento: Ocupar, resistir, produzir ${ }^{3}$. Nos anos 1990, por outro lado, houve uma nova readequação tática, adotando-se as grandes jornadas nacionais como principal forma de luta. Dessa maneira, o MST alcançava maior visibilidade e contato com as periferias das grandes cidades, num claro movimento de expansão para o território urbano (MOVIMENTO DOS TRABALHADORES RURAIS SEM TERRA, 1997a). E, finalmente, a partir de fevereiro de 2000, iniciou-se um novo momento com a adoção da agroecologia como orientação política e principal estratégia de luta, que se ampliou nos anos posteriores.

Neste trabalho nos debruçaremos sobre este último período de reorganização político-estratégica do MST. A pesquisa tem como recorte temporal o período compreendido entre 2000 e 2016 . O marco final foi delimitado pelo término de um período político com a deposição da presidenta Dilma Rousseff. Os resultados da nossa pesquisa apontam para a existência contraditória de elementos que definem e articulam dois caminhos opostos: por um lado, a abertura de uma via de autonomia intelectual, política e econômica a partir de uma organização interna permanente, construída ao longo dos anos, capaz de prover educação e formação técnica e política para uma porção significativa de trabalhadores rurais e, por outro, um processo de absorção e subalternização de lideranças sem-terra, assim como dos intelectuais ligados a elas, aos governos do Partido dos Trabalhadores (PT), entre 2003 e 2016. Este processo redundou em um esvaziamento dos conteúdos políticos e no enfraquecimento das ações reivindicativas do MST e, consequentemente, na perda de radicalidade da luta pela terra que contribuiu para o estancamento da reforma agrária no Brasil.

Para consecução dos nossos objetivos, partimos das indicações teóricas e metodológicas de A. Gramsci, especialmente nos Quaderni del Carcere. O autor advertiu sobre a necessidade de fazer ciência social a partir de um ponto de vista monográfico, sobretudo, quando se trata da formação de grupos sociais subalternos, uma vez que sua história é desagregada, episódica e subterrânea, subvertida sob as ideologias dominantes (GRAMSCI, 2007). Para o estudo do MST, portanto, não partimos apenas da análise morfológica de suas estruturas, mas também da sua formação histórica, das suas concepções teóricas e práticas, projetos e ideologias, assim como as conexões com os demais grupos na sociedade civil e com o Estado. Os dados analisados foram colhidos, sobretudo, nos documentos internos do MST, atas de congresso, materiais que orientam a direção nas instâncias educativas e regimento interno. De forma suplementar, além de pesquisa bibliográfica, lançamos mão da observação participante no assentamento Pontal do Tigre, onde está a Cooperativa de Comercialização e Reforma Agrária Avante LTDA (COANA) em Querência do Norte-PR, na Escola Milton Santos em MaringáPR e no assentamento de Reforma Agrária Celso Furtado, na região do brejo paraibano.

Para exposição dos resultados da pesquisa, em primeiro lugar, trataremos brevemente da estrutura organizativa do MST, que possibilitou a inserção da pauta dos trabalhadores rurais sem-terra na agenda pública de debates. Em seguida, apresentaremos os elementos principais que caracterizam o novo momento do MST, marcado pela adoção da agroecologia e pela educação ambiental popular. Concluiremos com a exposição dos resultados relativos à investigação que se referem diretamente às potencialidades atuais do MST na luta pela reforma agrária e pela educação ambiental no Brasil. 


\section{A forma política do MST}

De seu primeiro ciclo de vida fomentado pelas CEBs e pela CPT até a consolidação de direções de trabalhadores sem-terra formados pelo próprio movimento, o MST construiu uma estrutura política hierárquica e centralizada no interior do movimento de massas. Desse modo, se institucionalizou e assimilou estruturas dos partidos políticos de origem extraparlamentar que, em síntese, são aqueles que não se constituem a partir do mecanismo eleitoral e parlamentar, mas comumente são estabelecidos por uma instituição preexistente (sindicatos, igrejas, sociedades de pensamento, associações etc.), cuja própria atividade se situa fora das eleições e do parlamento. Os partidos de origem extraparlamentar estão empenhados, sobretudo, em "promover certos valores espirituais e morais na vida política, o que imprime à ação educativa um lugar tão importante quanto as lutas eleitorais" (DUVERGER, 1970, p. 32).

A estrutura organizativa do MST, que carrega uma importante herança da agremiação popular das CEBs, a partir das quais o movimento constituiu suas primeiras ações coletivas, está estruturada por um heterogêneo conjunto de princípios teóricos e práticos que unem valores cristãos e socialistas, herdados da Teologia da Libertação, com centralidade na educação popular. Esta estrutura é composta por uma cadeia complexa de congressos e encontros nacionais e estaduais, direções e coordenações nacionais e estaduais, geridas por funcionários especializados, além das instâncias de base, que possuem seus representantes e secretarias (ALIAGA, 2017).

Embora o surgimento do MST se deva a uma demanda específica pela reforma agrária, em sua trajetória o movimento expandiu seus objetivos iniciais, colocando-se num plano de ação mais amplo, propondo-se à construção da hegemonia de seu grupo fundamental, os trabalhadores rurais, assumindo, assim, funções de um partido político, isto é, funções de organização e direção política de classe. Para Gramsci, em determinadas situações, as funções de partido podem ser exercidas por outros organismos sociais, que se tornam, por isso, verdadeiros partidos na medida em que organizam e dirigem o consenso de acordo com os interesses de determinados grupos, mesmo sem se apresentarem deste modo, como, por exemplo, alguns jornais e revistas italianos do início do século XX (GRAMSCI, 2007, p. 1939). Avançamos aqui, portanto, na tese de que o MST assumiu uma forma-partido, caracterizada pelas estruturas organizativas descritas acima, na medida em que se encarregou das funções específicas dos partidos políticos de origem extraparlamentar, isto é, da organização (o que inclui a educação e a formação intelectual e política) e direção de classe ${ }^{4}$.

A função de direção e organização de classe se refere à expansão política dos interesses específicos dos trabalhadores rurais sem-terra, absorvendo, assim, os interesses dos demais trabalhadores rurais e urbanos, articulando-os em um projeto popular e autônomo de sociedade. Esta expansão da classe constitui elemento fundamental para construção de uma nova hegemonia e pode ser observada entre os objetivos do projeto popular do MST:

O esforço para realizar essa construção política consiste basicamente em articular os atores, verdadeiramente interessados na concretização dos objetivos estratégicos: terra, trabalho, moradia e educação. Esses atores são: o operariado industrial do setor formal e informal, o campesinato, entendendo-se pela expressão: os sem-terra, o produtor familiar e o assalariado rural; os empregados de baixa renda do setor de serviços (balconistas, artesãos, pequenos funcionários públicos) e os excluídos das cidades e dos campos. É preciso amalgamar esses imensos contingentes sociais em um bloco político capaz de travar em conjunto uma luta decisiva contra as classes dominantes. [...]. (MOVIMENTO DOS TRABALHADORES RURAIS SEM TERRA, 1997b, p. 8, grifo nosso).

A construção de uma organização política no interior do movimento de massas contribuiu para garantir estabilidade ao MST, superando a fluidez característica dos movimentos sociais (GOHN, 1997). Tornou-o um sujeito político relevante, capaz de organizar amplos setores do campo e influenciar também o ambiente político urbano, estabelecendo-se em todas as regiões do Brasil. Desse modo, o projeto de reforma agrária do MST ampliou-se e assumiu a forma de um projeto nacional-popular ${ }^{5}$. 


\section{O projeto popular, a reforma agrária e a agroecologia}

A agroecologia como orientação política foi adotada no IV Congresso Nacional em fevereiro de 2000. Naquele momento avaliava-se os impactos da falta de autonomia financeira em relação aos recursos públicos, bem como a dependência do mercado de insumos e agrotóxicos. Além disso, o surgimento da Via Campesina ${ }^{6}$ colocou em contato diversas lideranças de movimentos sociais internacionais, que já haviam incorporado a questão ambiental em suas pautas e agregado novos referenciais teóricos para produção (BORGES, 2007).

Como prerrogativas para desenvolver este novo projeto, o MST elencou uma série de medidas a serem reivindicadas ao Estado, colocando no centro de suas demandas o desenvolvimento de programas massivos de formação em agroecologia em todos os níveis, desde o ensino fundamental até a universidade; o estímulo à produção independente de sementes, que preservassem a diversidade genética vegetal e animal por parte dos próprios agricultores e agricultoras, evitando cenário estanques como o das sementes terminator ${ }^{7}$ (STEDILE, 2013, p. 156). Por esta via de ampliação das demandas populares, a base da Reforma agrária popular se estendeu também para as comunidades originárias, povos indígenas, ribeirinhos, seringueiros, geraizeiros, quilombolas e movimento de mulheres (CARVALHO, 2013, p. 130).

A aplicação prática deste programa no ambiente de produção exigiu adequações importantes na formação político-pedagógica do MST, especialmente no que se referia à inteiração orgânica entre teoria e prática, direção e base (MOVIMENTO DOS TRABALHADORES RURAIS SEM TERRA, 2009, p. 8). Sendo assim, a "metodologia popular" buscada repelia um "método cheio de técnicas" em favor do "enraizamento na vida da população, animando e organizando os trabalhadores na busca de solução para seus problemas" (MOVIMENTO DOS TRABALHADORES RURAIS SEM TERRA, 2009, p. 24). Desse modo, dedicado à educação ambiental popular centrada na autonomia intelectual, política e econômica, o MST buscou o equilíbrio entre a necessidade prática dos modelos teórico-científicos e a valorização dos conhecimentos populares, evitando, contudo, os riscos de acomodar-se às elaborações acríticas que se acumulam na vida cotidiana das massas ${ }^{8}$.

Em função dessa nova valorização da autoeducação ambiental popular, além do projeto de implantação da agroecologia em seus assentamentos e cooperativas de produção, o MST buscou estabelecer cursos em cerca de 30 escolas no Brasil, a maioria concentrada na região Sul. Os cursos foram realizados em parceria com instituições públicas de ensino, através de recursos do Programa Nacional de Educação na Reforma Agrária (Pronera), certificados pelo Instituto Federal do Paraná (IFPR) e pelo Instituto Nacional de Colonização e Reforma Agrária (INCRA) (NOVAES et al., 2016).

Embora enfrentassem muitas contingências para concretização de seu plano político-pedagógico, entre elas a escassez de recursos de manutenção e o baixo incentivo das universidades em pesquisas na área agroecológica, enquanto campo de conhecimento abrangente, a agroecologia representou um importante avanço para a constituição de sujeitos autônomos, resistentes à racionalidade instrumental capitalista. Nesse sentido, a educação popular agroecológica foge da homogeneidade epistemológica do "positivismo acrítico" da mesma forma que rejeita a epistemologia hiperindividualizante pós-moderna, sendo assim, busca uma compreensão histórica dos fenômenos sociais e da identidade parcial entre sujeito e objeto, entre teoria e prática (NOVAES et al., 2016). Elementos políticos e epistemológicos fundamentais para a emancipação dos subalternos.

\section{MST entre autonomia e subalternidade}

Ainda que muito aquém dos orçamentos destinados às grandes unidades produtivas agrícolas ${ }^{9}$, durante os primeiros anos do governo do Partido dos Trabalhadores (PT), que se iniciaram em 2003, as ONGs ligadas ao MST foram as que contaram com o maior aumento no orçamento. Dos três últimos anos da administração Fernando Henrique Cardoso (PSDB) - 2000 a 2002 - para os três primeiros anos de mandato de Luís Inácio Lula da Silva (doravante Lula) (PT), a verba repassada à Associação Nacional de Cooperação Agrícola (Anca), à Confederação das Cooperativas de Reforma Agrária (Concrab) e ao Instituto Técnico de Capacitação e Pesquisa da Reforma Agrária (Iterra) praticamente quadriplicou, de R 7 milhões para R \$ 30 milhões (SALOMON; PAGNAN, 2006). 
Entre as entidades beneficiadas, destaca-se o ITERRA, principal fonte de organização e realização de projetos educacionais do MST e um dos principais vetores de concretização da produção agroecológica, por meio de cursos de capacitação, formação técnica e política. Do ponto de vista político-administrativo, houve também o estabelecimento de importantes compromissos entre PT e MST com a nomeação de Marcelo Resende ${ }^{10}$ como presidente do INCRA, em janeiro de 2003, acompanhado de um total de 29 superintendentes com vinculações ao MST. Apesar das íntimas relações com o governo, o número de ocupações continuou estável no primeiro mandato do PT. Mas, por outro lado, a reforma agrária apresentou estagnação já a partir de 2003 (GIRARDI, 2020).

Entre o final de 2006 e início de 2007, contudo, observou-se uma desaceleração no número de ocupações de terra e diminuição das famílias acampadas, que até o fim do segundo mandato da presidente Dilma Rousseff (PT, 2011-2016) foi sobremaneira menor do que nos governos precedentes aos petistas (PEREIRA, 2019). Outro dado importante a ser observado mostra que entre maio e agosto de 2006, os números de ocupações caíram mais que a metade, ao mesmo tempo em que os benefícios orçamentais cresceram. Lula havia se declarado o único candidato capaz de conter os Sem-terra (SALOMON; PAGNAN, 2006), e, de fato, o número de ocupações caminhava em decrescimento no início de seu segundo mandato.

A despeito de o MST organizar ações de grande repercussão nacional, como a destruição do centro de pesquisas da Aracruz Celulose ${ }^{11}$, no Rio Grande do Sul, neste período o MST não retomou o fluxo de ocupações (GALLAS; FACHIN, 2014). O movimento decadente da participação das famílias sem-terra na luta pela reforma agrária acompanhou o decréscimo nos índices da reforma agrária a partir de 2003. O Plano Nacional de Reforma Agrária (PNRA) aprovado em 2003 previa o assentamento de 430 mil famílias em quatro anos. Segundo o DATALUTA, de 2003 a 2005 foram assentadas 244.289 famílias, contudo apenas 25\% das famílias foram assentadas em terras desapropriadas, enquanto 183.202 famílias foram assentadas em "assentamentos já existentes ou em assentamentos implantados em terras públicas" (GIRARDI, 2020). Pelo menos um terço dessas famílias foram assentadas em projetos extrativistas, reservas e assentamentos feitos pelos estados.

O ritmo decrescente de desapropriações de terra indica uma política de governo mais voltada para medidas compensatórias do que propriamente para um projeto de reforma agrária. Em 2006 foram desapropriados 538,6 mil hectares, enquanto em 2007 apenas 204,5 mil hectares. A área, suficiente para assentar apenas 6.000 famílias, representava pouco menos de um terço da média anual de 682,5 mil hectares do primeiro mandato (GALLAS; FACHIN, 2014). Esses números indicam que a estrutura fundiária não foi profundamente alterada, a concentração de terras conservava-se na medida em que os grandes latifúndios improdutivos não foram desapropriados para Reforma Agrária. Enquanto isso, os índices de famílias atendidas pelo programa assistencial Bolsa Família ${ }^{12}$ apresentavam uma tendência crescente. Em 2003, 3,6 milhões de famílias foram beneficiadas, em 2006 o programa Bolsa Família atingiu 10,9 milhões de famílias. Os recursos passaram de 570,1 milhões para 7,5 bilhões de reais neste período (SOUZA et al., 2019). A exigência de residência fixa para o recebimento do benefício dificultou que famílias acampadas ou em processo de assentamento tivessem acesso aos recursos. Diante disso, muitas delas desistiram da militância na luta pela terra, fragilizando assim as bases dos movimentos sociais.

No primeiro mandato, Lula manteve os movimentos sob controle, à espera de transformações reais, sob a justificativa de que a manutenção das políticas neoliberais seria transitória, "que era apenas uma ponte para evitar chantagem, para evitar bloqueio, para evitar uma agudização da crise econômica, tal o grau de dependência financeira em que o Brasil estava" (STÉDILE, 2006, p. 144). Com o passar do tempo, entretanto, os movimentos perceberam - segundo Stédile - que as políticas neoliberais de Lula não eram transitórias e sim programáticas. Acreditavam, contudo, que o governo ainda estava em disputa. Segundo avaliação das lideranças sem-terra, no interior do governo Lula haveria duas tendências político-ideológicas distintas: uma tendência conservadora, neoliberal, com influência, sobretudo, na área econômica e uma tendência progressista, influente na área social. Lula estaria entre os progressistas e por esta razão não seria inimigo do MST. (FEIX, 2005). Nesse cenário a tarefa que caberia ao MST seria "empurrar o governo para fazer mudanças".

As lideranças do MST, no entanto, deixavam transparecer a confusão e a perplexidade diante dos novos rumos de seu aliado histórico. Suas análises eram desencontradas e ambíguas, pois, ao mesmo tempo em que acreditavam ter como aliado o presidente, criticavam a política do governo federal, como se os dois pudessem ser separados de forma a não haver uma contaminação neoliberal sobre Lula. A orientação neoliberal seria apenas o reflexo da proeminência das elites na relação de forças em disputa pela orientação da política 
econômica do país. Diante desta relação de forças desfavorável, os movimentos populares entendiam que um rebaixamento de programa seria uma forma de aglutinar forças, isto é, acreditavam que um governo nacionaldesenvolvimentista ainda seria possível com Lula. Em relação ao projeto democrático-popular dos anos 1990 isto significava um retrocesso, mas em comparação com o neoliberalismo poderia representar um avanço, de forma que foram toleradas as alianças com partidos conservadores como o Partido Liberal (PL) do vicepresidente José Alencar (STEDILE, 2006).

O que aconteceu a partir de 2005, no entanto, foi um refluxo das lutas sociais. Por diversos caminhos houve uma assimilação do MST aos governos petistas. Isso pode ser explicado em primeiro lugar pelo fato de MST e PT serem ramos do mesmo cepo, isto é, as duas organizações floresceram sob o auspício dos mesmos grupos políticos, especialmente aqueles organizados nas CEBs. Segundo Stédile, o MST ajudou na fundação do PT em várias regiões do país e "muitas lideranças que surgiram da luta pela terra passaram a militar no partido como dirigentes ou como parlamentares" (STEDILE; FERNANDES, 1999, p. 36). Em função disso, PT e MST possuem militantes em comum, entre os quais está o mais destacado dirigente sem-terra - João Pedro Stédile (STEDILE, 2006, p. 178). Essa ligação duradoura entrou em entropia política quando o PT ascendeu ao governo e, de aliado na luta pela reforma agrária, tornou-se um entrave para ela. A esta situação aliaram-se as indicações do MST para postos no Estado e o aumento do financiamento público para ONGs e cooperativas ligadas ao movimento.

Ao final o que se observou foi um esvaziamento da radicalidade das reivindicações dos sem-terra e o estancamento da reforma agrária. Esse processo de absorção molecular de lideranças nascidas das lutas populares pelo Estado foi definido por Gramsci como transformismo. Este fenômeno político tem como resultado principal o esvaziamento do conteúdo original das reivindicações dos subalternos, impactando diretamente em sua desorganização e na retirada de seu potencial disruptivo, subordinando-os à direção burocrático-política do Estado (GRAMSCI, 2007, p. 41).

Conforme ressaltam Bianchi e Braga (2005, p. 1753), ao contrário de representar uma alternativa ao modo de fazer política no Brasil, o programa do PT afirmou uma lógica de Estado com uma visão de desenvolvimento gradual da estrutura econômica do capitalismo brasileiro por meio de sucessivas mudanças dirigidas pelo Estado, evitando a intervenção ativa das classes subalternas neste processo. O PT governo - dizem os autores - "faz este exorcismo do possível mal e valoriza o que de bom o mercado apresenta, humanizando-o" (BIANCHI; BRAGA, 2005, p. 1753). Este raciocínio de administração da presente estrutura econômica em busca de um capitalismo humanizado mutila a dialética porquanto a restringe a "um jogo de oposições entre o bom e o mau". A anulação política dos fatores indesejáveis ao tipo de capitalismo prognosticado pelo PT suprimiu os polos de oposição da dialética superação, permitindo a recriação da situação em novas bases. "O resultado desta operação é uma constante reprodução da existência anterior por meio de um processo de aperfeiçoamento e harmonização do real" (BIANCHI; BRAGA, 2005, p. 1753).

Nesse contexto, o projeto de educação ambiental popular e de implantação da agroecologia do MST coincidiu com opções político-estratégicas de menor radicalidade na luta pela terra, de modo que o próprio projeto popular de reforma agrária sofreu importantes retrocessos. Concomitantemente, o movimento estabeleceu laços cada vez mais sólidos com o Estado, assumindo compromissos político-administrativos e orçamentários que absorveram sua capacidade de reinvindicação. Estes compromissos resultaram na sua subordinação à direção burocrático-estatal, contribuindo para a permanência da estrutura fundiária extremamente concentrada no latifúndio e no pouco avanço dos projetos de agroecologia.

\section{Considerações Finais}

Como procuramos demonstrar, o MST é resultado da auto-organização política popular de um amplo contingente de famílias despossuídas da terra, que reagiu contra a precarização da vida no campo. O projeto de Reforma agrária popular e a matriz agroecológica de fato abriram espaço para novas perspectivas dentro e fora do movimento, formando alianças em toda região latino-americana. A construção da forma partido, nesse sentido, foi essencial para o desenvolvimento de um projeto nacional capaz de orientar a ação organizada e unificada do movimento. Do mesmo modo, o fomento à educação ambiental e à formação política forneceram qualificação intelectual e técnica a parcelas expressivas dos trabalhadores rurais sem-terra, abrindo uma 
importante via de autonomia popular e possibilidade de emancipação política para as classes subalternas do campo e, em menor grau, também da cidade.

Contraditoriamente, os avanços na educação e formação internas, que potencialmente conduziriam à expansão política das classes subalternas e a formação de uma nova hegemonia colidiram com um sólido obstáculo: os compromissos com um partido político que agora geria o Estado e a consequente assimilação do MST ao governo. A neutralização do conflito na luta pela terra provocada pelos vínculos entre MST e PT fragilizou a luta dos sem-terra. Tal fragilidade se expressou principalmente na perda substantiva do poder de pressão em favor da reestruturação fundiária. A agroecologia, assim, se manteve à sombra do agronegócio, substituindo a radicalidade das ocupações de terra, de prédios públicos e as grandes marchas nacionais pela convivência pacífica com o Estado. O projeto agroecológico do MST, desse modo, colaborou com os princípios populares que se tornaram "direção moral" dos governos petistas, no entanto, a direção concreta, a política econômica do Estado, sobretudo, foi entregue ao capital financeiro e às oligarquias fundiárias. Desse modo, parafraseando Francisco de Oliveira (2010), pode-se dizer que na hegemonia às avessas brasileira no período estudado não foram apenas os dominados que consentiram em sua própria exploração; mas também os dominantes consentiram em ser politicamente conduzidos pelos dominados, tornando a dominação ainda menos visível e, por isso mesmo, mais sólida.

\section{Referências}

ALIAGA, L. "Movimento social e organização política". In SILVA, H. A. Sob os olhos da crítica: reflexões sobre democracia, capitalismo e movimentos sociais. Macapá: UNIFAP, 2017.

ALIAGA, L. A forma política do MST. (Dissertação de Mestrado). Campinas: Universidade Estadual de Campinas, 2008.

BIANCHI, A; BRAGA, R. "Brazil: the Lula government and financial globalization”. Social Forces, Chapel Hill, v. 83, n. 4, 2005.

BORGES, J. L. A transição do MST a agroecologia. 2007. Dissertação (Mestrado em Ciências Sociais) - Universidade Estadual de Londrina, Londrina, 2007.

CARTA CAPITAL. Brasil pode ser o primeiro País a liberar semente Terminator. Terra de Direitos, São Paulo, 9 nov. 2015. Disponível em: https://terradedireitos.org.br/noticias/terra-de-direitos-na-midia/carta-capital-brasil-pode-ser-o-primeiro-pais-a-liberar-sementeterminator/19105. Acesso em: 16 maio 2021.

CARVALHO, H. M. “Uma ressignificação para a reforma agrária no Brasil”. In: CARVALHO, H. M.; STÉDILE, J. P. A questão agrária no Brasil: Debate sobre a situação e perspectivas da reforma agrária na década de 2000. São Paulo: Expressão Popular, 2013, p. $127-141$. DUVERGER, M. Os Partidos Políticos. Rio de Janeiro: Zahar, 1970.

FEIX, P. J. “A Democracia no Projeto Revolucionário do MST: Uma análise da visão revelada por lideranças”. In: MARKUS, M. E.; FEIX, P. J. (org.). Fazendo História no Cerrado. Rondonópolis: Styllus, 2005.

FERNANDES, B. M. A Formação do MST no Brasil. Petrópolis: Editora Vozes, 2000.

GALLAS, L.; FACHIN, P. "Está em curso uma concentração da propriedade da terra", diz Stedile. Movimento dos Trabalhadores Rurais sem Terra, [s.l.], 16 maio 2014. Disponível em: https://mst.org.br/2014/05/16/esta-em-curso-uma-concentracao-da-propriedadeda-terra-diz-stedile/. Acesso em: 16 maio 2021.

GIRARDI, E. P. Rede Dataluta. UNESP, São Paulo, 19 jun. 2020. Não paginado. Disponível em: https://www.fct.unesp.br/\#!/pesquisa/ dataluta. Acesso em: 16 maio 2021.

GOHN, M. da G. Teoria dos movimentos sociais: paradigmas clássicos e contemporâneos. São Paulo: Loyola, 1997.

GRAMSCI, A. Quaderni del carcere: edizione critica dell'Istituto Gramsci a cura di Valentino Gerratana. Torino: Einaudi, 2007.

LA VÍA CAMPESINA. Las luchas del campesinato em el mundo. Ehne, 2009.

MARANHO, F. P. A agroecologia como orientação política no MST Caminho para emancipação nacional popular ou para o transformismo? (Dissertação de Mestrado). João Pessoa: UFPB, 2019.

MOVIMENTO DOS TRABALHADORES RURAIS SEM TERRA (MST). Caderno de formação 38: trabalho de base e formação popular. São Paulo: MST, 2009.

MOVIMENTO DOS TRABALHADORES RURAIS SEM TERRA (MST). Diretrizes para o projeto nacional. MST, novembro de $1997 \mathrm{~b}$. MOVIMENTO DOS TRABALHADORES RURAIS SEM TERRA (MST). Elementos Fundamentais da História do MST. MST, julho, 1997a.

MINISTÉRIO DA AGRICULTURA PECUÁRIA E ABASTECIMENTO - MAPA. MAPA, 2016. Ministério. Disponível em: <http:// www.agricultura.gov.br/ministerio>. Acesso em: 18 junho 2018. 
MINISTÉRIO DO DESENVOLVIMENTO AGRÁRIO - MDA, 2016. Histórico. Disponível em: <http://www.mda.gov.br/sitemda/ pagina/histórico>. Acesso em: 18 junho 2018.

MOREIRA, F.G. et al. (org.). As causas da violência no campo: terra renda e poder. Conflitos no Campo Brasil, Goiânia, v. 1, p. 3439, abr. 2005. Anual.

NAVARRO, Z. "Mobilização sem emancipação - as lutas sociais dos sem-terra no Brasil”. In: SANTOS, B. de S. (org.). Produzir para Viver, Rio de Janeiro: Editora Civilização Brasileira, 2002.

NOVAES, H.T. et al. A economia política da "revolução verde", a agroecologia e as escolas de agroecologia do MST. In: NOVAES, H.; MAZIN, A. D.; SANTOS, L. (org.). Questão Agrária, cooperação e agroecologia. 2. ed. São Paulo: Outras Expressões, 2016. p. $209-231$. OLIVEIRA, F. "Hegemonia às avessas”. In: OLIVEIRA, F.; BRAGA, R.; RIZEK, C. Hegemonia às avessas: economia, política e cultura na era da servidão financeira. São Paulo: Boitempo, 2010.

PASSOS, C. Assassinatos no campo batem novo recorde e atingem maior número desde 2003. Comissão Pastoral da Terra, Goiânia, 16 abr. 2018. Disponível em: https://www.cptnacional.org.br/publicacoes-2/destaque/4319-assassinatos-no-campo-batem-novo-recordee-atingem-maior-numero-desde-2003. Acesso em: 16 maio 2021.

PEREIRA, L. I. et al. Análise da questão agrária brasileira em 2017: criação de assentamentos rurais, ocupações de terras, manifestações do campo e estrangeirização da terra. São Paulo: NERA, 2019.

RUBBO, D. A. I. Párias da terra: o MST e a mundialização da luta camponesa. São Paulo: Alameda, 2012.

SALOMON, M.; PAGNAN, R. União repassou R 60 mi a entidades pró-Lula. Folha UOL, São Paulo, 30 abr. 2006. Disponível em: https://www1.folha.uol.com.br/fsp/brasil/fc3004200613.htm. Acesso em: 16 maio 2021.

SOUZA, P. et al. Os efeitos do Programa Bolsa Família sobre a pobreza e a desigualdade: um balanço dos primeiros quinze anos. Brasília: IPEA, 2019.

STÉDILE, J. P. "Sair da crise com a energia do povo". In: CHAUÍ, M. et al. Leituras da Crise: diálogos sobre o PT, a democracia brasileira e o socialismo. São Paulo: Perseu Abramo, 2006.

STÉDILE, J. P. A questão agrária no Brasil: debate sobre a situação e perspectiva da reforma agrária na década de 2000. São Paulo: Expressão Popular, 2013.

STÉDILE, J. P.; FERNANDES, B. M. Brava Gente: a trajetória do MST e a luta pela terra no Brasil. São Paulo: Fundação Perseu Abramo, 1999.

\section{Notas}

1 A formação oficial do Movimento dos Trabalhadores Rurais Sem Terra ocorreu em seu $1^{\circ}$ Encontro Nacional, em janeiro de 1984, em Cascavel-PR, entretanto sua constituição pode ser datada a partir de sua primeira ocupação em setembro de 1979, quando 110 famílias ocuparam a gleba Macali, em Ronda Alta-RS, lideradas pelo Padre Arnildo Fritzen, ligado à Comissão Pastoral da Terra (FERNANDES, 2000).

2 Os índices de violência no campo, que sempre foram altos, vêm aumentando a partir de 2015 (PASSOS, 2018).

3 Em 1985 o lema era: "Sem Reforma Agrária não há democracia”; em 1986: "Ocupação é a única solução" e no período de 1988 a 1990 passa a ser "Ocupar, Resistir, Produzir". (MOVIMENTO DOS TRABALHADORES RURAIS SEM TERRA, 1997, p. 2).

4 Para uma discussão mais detida sobre o tema consultar ALIAGA, 2008.

5 Sobre isso consultar o documento preparatório para o IX Encontro Nacional do Movimento, "Diretrizes para o projeto nacional" (MST, 1997b, p. 1).

6 Fundada em abril de 1992, a Via Campesina é uma organização internacional de defesa dos direitos dos trabalhadores rurais em diferentes continentes (LA VÍA CAMPESINA, 2009, p. 8). Sobre este tema ver também Rubbo (2012).

7 Conhecidas como sementes suicidas são plantas desenvolvidas propositalmente para serem estéreis, impassíveis de reprodução, o que gera a necessidade de que todo início de plantio os agricultores adquiram novas sementes. A preocupação dos ambientalistas em liberar esse tipo de semente no Brasil, que seria o primeiro país do mundo a aceitar o uso dentro da lei, é de que as sementes podem se espalhar de forma imprevisível pelo país, ameaçando os biomas locais, inclusive o amazônico (CARTACAPITAL, 2015).

8 Para uma análise mais detida sobre o tema, consultar MARANHO, 2019.

9 A divisão dos ministérios responsáveis pelas questões agrárias demonstra em orçamentos, poderes de vetos e projetos de lei, a correlação de força entre agronegócio e reforma agrária. Vemos que o Ministério da Agricultura, Pecuária e Abastecimento (MAPA), responsável pelas políticas de crédito ao agronegócio, planos agrícolas e pecuários, sintetizados no lema "estratégia de abertura ao mercado internacional" contava até o limite do nosso recorte, 2016, com um orçamento anual em média de R\$187,7 bilhões (MINISTÉRIO DA AGRICULTURA, PECUÁRIA E ABASTECIMENTO, 2016). O contraponto dado pelo Ministério do Desenvolvimento Agrário (MDA), que tinha como incumbência as políticas de reforma agrária, promoção do desenvolvimento 
sustentável do segmento rural; contava com um orçamento de $\mathrm{R} \$ 28,9$ bilhões, sendo esse o maior valor já destinado a essa pasta desde sua criação (MINISTÉRIO DO DESENVOLVIMENTO AGRÁRIO, 2016).

1 Marcelo Resende é geógrafo, nascido em Minas Gerais, possui especialização em Direitos Humanos e Cidadania. Membro histórico da Comissão Pastoral da Terra (CPT), foi também membro da Rede Social de Justiça e Direitos Humanos. Primeiro presidente do INCRA no Governo Lula e ex-presidente do Instituto de Terras de Minas Gerais no Governo Itamar Franco (MOREIRA et al., 2005).

11 Sobre este mesmo episódio ver Stédile (2013).

12 Programa Bolsa Família (PBF) destina-se a famílias em situação de pobreza. Para recebê-lo, a família precisa ter, entre outras exigências, residência fixa.

\section{Luciana Aliaga}

lualiagaa@gmail.com

Doutora em Ciência Política pela Unicamp (UNICAMP)

Professora adjunta do Departamento de Ciências Sociais e do Programa de Pós-graduação em Ciência Política e Relações Internacionais da Universidade Federal da Paraíba (UFPB)

\section{Fernanda Peres Maranho}

fernandapmaranho@gmail.com

Mestre em Ciência Política pelo Programa de Pós-graduação em Ciência Política e Relações Internacionais da Universidade Federal da Paraíba - UFPB.

\section{UFPB}

Campus I - Lot. Cidade Universitária

João Pessoa - PB - Brasil

CEP 58051-900

\section{Agência financiadora}

Não se aplica.

Contribuições das autoras

Autora: pesquisa e construção de parte da argumentação, redação da estrutura básica do artigo e revisão final. Coautora: pesquisa e construção de parte da argumentação, revisão final.
Aprovação por Comitê de Ética

Não se aplica.

Consentimento para publicação

Consentimento das autoras.

Conflito de interesses

Não se aplica. 